\title{
Characterization of calcineurin from Cryptococcus humicola and the application of calcineurin in aluminum tolerance
}

\author{
Lei Zhang ${ }^{\dagger}$, Jing-jing Zhang ${ }^{\dagger}$, Shuai Liu, Hong-juan Nian ${ }^{*}$ and Li-mei Chen
}

\begin{abstract}
Background: Calcineurin ( $\mathrm{CaN}$ ) is a $\mathrm{Ca}^{2+}$ - and calmodulin (CaM)-dependent serine/threonine phosphatase. Previous studies have found that $\mathrm{CaN}$ is involved in the regulation of the stress responses.

Results: In this study, the growth of Cryptococcus humicola was inhibited by the CaN inhibitor tacrolimus (FK506) under aluminum (Al) stress. The expression of CNA encoding a catalytic subunit A (CNA) and its interaction with CaM were upregulated when the concentration of Al was increased. A CaM-binding domain and key amino acids responsible for interaction with CaM were identified. $\triangle$ CNAb with a deletion from S454 to A639 was detected to bind to CaM, while $\triangle \mathrm{CNAa}$ with a deletion from R436 to A639 showed no binding to CaM. The binding affinities of CNA1 and CNA2, in which 1439 or 1443 were replaced by Ala, were decreased relative to wild-type CNA. The phosphatase activities of $\triangle \mathrm{CNAa}, \mathrm{CNA} 1$ and $C N A 2$ were lower than the wild-type protein. These results suggest that the region between R436 and S454 is essential for the interaction with CaM and 1439, 1443 are key amino acids in this region. The ability of the CNA transgenic yeast to develop resistance to Al was significantly higher than that of control yeast. Residual Al in the CNA transgenic yeast culture media was significantly lower than the amount of Al originally added to the media or the residual Al remaining in the control yeast culture media. These findings suggest that CNA confers Al tolerance, and the mechanism of Al tolerance may involve absorption of active Al.

Conclusions: Al stress up-regulated the expression of CNA. CaM-binding domain and key amino acids responsible for interaction with CaM were identified and both are required for phosphatase activities. CNA conferred yeast Al resistance indicating that the gene has a potential to improve Al-tolerance through gene engineering.
\end{abstract}

Keywords: Cryptococcus humicola, Calcineurin, Calmodulin-binding domain, Transgenic yeast, Aluminum tolerance

\section{Background}

$\mathrm{Ca}^{2+}$ acts as one of the most diverse and widespread second messengers in cellular processes [1]. Calmodulin $(\mathrm{CaM})$ is a small, ubiquitous protein that acts as a calcium sensor to mediate several $\mathrm{Ca}^{2+}$ signals [2]. $\mathrm{CaM}$ is assumed to be involved in the activation of many enzymes, including CaM-dependent protein kinases and protein phosphatase (calcineurin) [3-5]. Calcineurin $(\mathrm{CaN})$ is a heterodimer consisting of a catalytic subunit A (CNA) and a regulatory subunit B (CNB) [6]. Although it is widely distributed, its primary sequence and structure is conserved among all eukaryotes. CNA

\footnotetext{
* Correspondence: hjnian@163.com

${ }^{\dagger}$ Equal contributors

Faculty of Life Science and Technology, Kunming University of Science and Technology, Kunming, China
}

contains a catalytic domain, a CNB-binding domain, a CaM-binding domain, and an autoinhibitory domain (AID) [7]. CaM binds to the CaM-binding domains on $\mathrm{CaN}$ and causes a conformational change that displaces an AID from the active site, which activates its phosphatase activity $[8,9]$.

$\mathrm{CaM}$ binding sequences on CNA are also called $\mathrm{CaM}$ recruitment signaling (CRS) motifs. A CaM target database (http://calcium.uhnres.utoronto.ca/ctdb) [10] has been built based on the structural and sequence information of the CRS motifs. This database can be used to predict whether a sequence contains a CaM-binding domain and to calculate the average hydrophobicity, the average hydrophobic moment, and the average propensity for a short peptide. Many $\mathrm{Ca}^{2+}$-dependent CRS motifs have been identified as $1-14$ or $1-10$ class [11]. 
Studies on these CaM-binding proteins revealed the possibility of interacting residues on CNA; however, there is no direct experimental evidence for the interaction.

Studies have shown that CaN play important roles in regulation of stress responses. In budding yeast (Saccharomyces cerevisiae), $\mathrm{CaN}$ is required to maintain cell viability during cation stress and pheromone-induced growth arrest [12-16]. Calcineurin-dependent genes are activated by heat and ionic stress as well as when the cell wall is destroyed [17-20]. Recent studies have established a role for $\mathrm{CaN}$ in responding to alkaline $\mathrm{pH}$ and endoplasmic reticulum (ER) stress [21, 22]. In Candida albicans, the main role of $\mathrm{CaN}$ is to respond to various stimuli or stress $[23,24]$. Under normal growth conditions, $\mathrm{CaN}$ is not required for growth in S. cerevisiae. Ethanol stress can activate the calcium-mediated calcineurin/Crz1 pathway [25]. CaN play a role in the vitality of filamentous fungi, where a deletion mutant of cna1 exhibited changes in growth efficiency, mycelium morphology and sporulation [26]. In C. albicans, a pathogen of human, mutants of the catalytic subunit of calcineurin (CMP1/CNA) and the calcineurin regulatory subunit (CNB1) are sensitive to salt stress, alkali stress and osmotic stress $[27,28]$.

$\mathrm{Al}$ exists in a trivalent cation $\left(\mathrm{Al}^{3+}\right)$ form under acid conditions, which is a toxic to animals, plants and microbes. Al toxicity is one of the factors limiting crop productivity in acid soils. Studies about the mechanisms of $\mathrm{Al}$ tolerance can provide insight to solve the problem of Al toxicity. Cryptococcus humicola is a high Alresistant yeast strain isolated from an acidic field [29]. In order to survive in acid soil, it has evolved Al-resistant mechanisms. Therefore, C. humicola can be used as a model for studying the mechanisms of $\mathrm{Al}$ toxicity and resistance. At the same time, the aluminum-resistant genes can be explored from $C$. humicola to improve the Al-tolerance of the crops. Our previous work proved that $\mathrm{CaM}$ signal pathway involve in response to $\mathrm{Al}$ stress. In Rhodotorula glutinis, an inhibitor of calcineurin completely inhibited the growth of under $\mathrm{Al}$ stress [30]. In this work, we aim to clone the gene of catalytic subunit of calcineurin (CNA) from C. humicola, analyze the expression of CNA under $\mathrm{Al}$ stress, identify the characteristics of interaction between $\mathrm{CNA}$ and $\mathrm{CaM}$, and prove the Al-tolerance ability of this gene in yeast. These results provide experimental data for the interaction between $\mathrm{CaM}$ and CNA and a theoretical reference for application of the gene in $\mathrm{Al}$-tolerance.

\section{Results}

The role of CNA in Al stress

To examine the impact of $\mathrm{CaN}$ on the growth of $C$. humicola under $\mathrm{Al}$ stress, FK506 was added to the culture medium containing $50 \mathrm{mM} \mathrm{Al}^{3+}$. As shown in (Fig. 1), the addition of $\mathrm{Al}$ or FK506 in liquid medium without $\mathrm{Al}$ slightly inhibited the growth of the strain. However, when FK506 was added to culture medium containing $\mathrm{Al}$, the growth of the strain was severely inhibited. These results suggest that $\mathrm{CaN}$ is involved in the growth of $C$. humicola under $\mathrm{Al}$ stress.

To study the transcription levels of CNA under $\mathrm{Al}$ stress, total RNA of cells treated with $\mathrm{Al}$ was used as the template for quantitative RT-PCR (qRT-PCR). As shown in (Fig. 2a and b), the expression of CNA increased gradually in cells treated with increasing concentrations or with the extension of treatment time. The expression level reached the maximum amount (5.9-fold and 1.9fold) when treated with $150 \mathrm{mM} \mathrm{Al} l^{3+}$ or treated for



Fig. 1 Effect of FK506 on the growth of C. humicola under Al stress. The initial $\mathrm{OD}_{600}$ of each culture was adjusted to 0.05, and FK506 was added to a final concentration of $1 \mu \mathrm{g} / \mathrm{mL}$. The culture was then incubated at $30^{\circ} \mathrm{C}$ while shaking at $200 \mathrm{rpm}$. The $\mathrm{OD}_{600}$ was measured every $2 \mathrm{~h}$. FK506: Inhibitor of CaN. CK: Al-free medium; Al: Medium containing 50 mM Al ${ }^{3+} ;$ CK+ FK506: FK506 was added to the medium without Al; Al + FK506: FK506 was added to the medium containing $50 \mathrm{mM} \mathrm{Al}^{3+}$. Each sample was in triplicate, and three independent experiments were conducted 

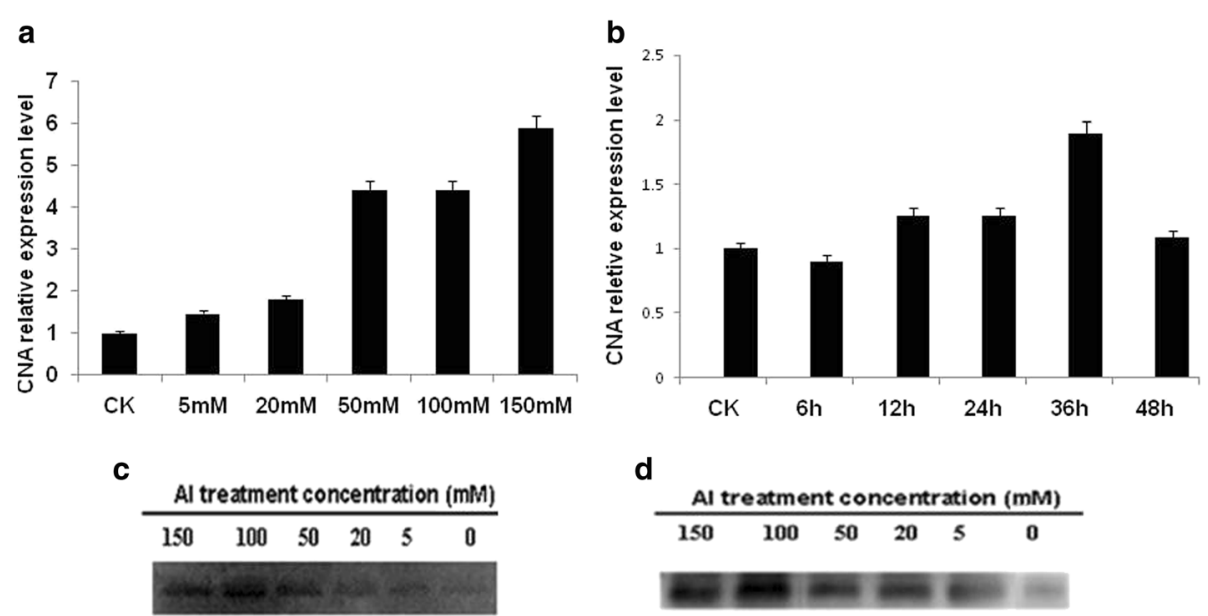

Fig. 2 Analysis of the expression level of CNA ( $\mathbf{a}, \mathbf{b}$ and $\mathbf{c})$ and interaction of CNA with CaM (d) under Al stress. qRT-PCR analysis of the transcription levels of CNA in the presence of different concentrations of $\mathrm{Al}(\mathbf{a})$ and different treatment time under $50 \mathrm{mM} \mathrm{Al}{ }^{3+}(\mathbf{b})$. The results were expressed as relative values with respect to $0 \mathrm{mM}$ or $0 \mathrm{~h}$, which were set to 1.0, respectively. The data are presented as the mean $\pm \mathrm{SE}(n=3)$. $\mathbf{c}$ Expression analysis of CNA under Al stress. Total protein was extracted from cells treated with 5, 20,50, 100, or $150 \mathrm{mM} \mathrm{Al}{ }^{3+}$. The membranes were probed with mouse antibodies against CNA and with peroxidase-conjugated goat antibodies against mouse lgG. $\mathbf{d}$ The interaction level of CNA with CaM under Al stress. Purified GST-CaM and total protein from cells treated by Al were incubated together. GST agarose resin was added. The interaction was detected with anti-CNA and a specific polyclonal anti-CaM antibody

$36 \mathrm{~h}$. To further study the expression of CNA in translational levels under Al stress, cultures of C. humicola treated with $\mathrm{Al}$ were collected. Western blot analysis was used to analyze the impact of $\mathrm{Al}$ stress on CNA protein levels. As shown in Fig. 2c, the expression of CNA protein gradually increased as the $\mathrm{Al}$ concentration increased. When the concentration of $\mathrm{Al}$ was $100 \mathrm{mM}$, the expression of CNA reached its maximum level. These results indicate that $\mathrm{Al}$ stress can affect the translation of the CNA and that CNA is involved in the response to Al stress in C. humicola.

To validate the effect of $\mathrm{Al}$ stress on the interaction between CaM and CNA, GST-pull downs and Western blot analysis were used. As shown in Fig. 2d, the binding level of CNA and CaM upon treatment with increasing concentrations of $\mathrm{Al}$ showed a gradual upward trend and reached a maximum level at concentration of $100 \mathrm{mM} \mathrm{Al}^{3+}$, indicating that interaction between $\mathrm{CaM}$ and CNA was also affected by $\mathrm{Al}$ treatment.

\section{Prediction of the CaM-binding domain and the binding residues of CNA}

We submitted the CNA sequence (GenBank accession no. KJ738305) to the CaM target database (http://calcium.uhnres.utoronto.ca/ctdb) [10], which includes almost all published CRS motif and obtained the putative CaMbinding domain sequence. The cDNA of CNA encodes a 71.5-kDa protein with a CaM-binding domain in its Cterminal region. The conserved hydrophobic residues in the CaM-binding domain, I439, I443, V446, and V452, form a 1-8-14 motif, which is probably involved in the interaction with CaM. I439 and F453 were predicted to be the anchor amino acids that possibly play an essential role in binding with CaM. Therefore, we decided to identify the roles of these five amino acids, which are shown in (Fig. 3), in binding with $\mathrm{CaM}$ and their role in activation of the phosphatase.

\section{Expression and purification of the recombinant proteins}

To determine the location of the CaM-binding domain in the CNA protein, a recombinant CNA protein of full length and two deletion mutants were expressed in $E$. coli as His-tagged fusion proteins. To identify the essential amino acids in the CaM-binding domain that bind to CaM, we constructed site-directed mutants of CNA. We mutated the five predicted amino acids to alanine. cDNA for CNA and all of the mutated CNAs were cloned into the pET-32a (+) vector, expressed in E. coli BL21 (DE3) cells, and then purified.

SDS-PAGE gels showed clear CaM recombinant protein bands at the position of the theoretical molecular weight of $42 \mathrm{kDa}$ (including the protein tag weight of $26 \mathrm{kDa}$ ). Similarly, CNA and their site-directed mutant protein (CNA1, CNA2, CNA3, CNA4, and CNA5) were shown at the position of $89.5 \mathrm{kDa}$ (including the protein tag weight of $18 \mathrm{kDa}$ ). The molecular weights of the truncated proteins $\triangle \mathrm{CNAb}, \triangle \mathrm{CNAa}$ were $70.2 \mathrm{kDa}$ and $67.3 \mathrm{kDa}$ (including the protein tag weight of $18 \mathrm{kDa}$ ), respectively (data not shown). 




Fig. 3 Partial nucleotide sequence of the CDNA for CNA and the deduced amino acids. The figures in the left and right margins indicate the amino acid and nucleotide positions, respectively. Italics represent the predicted CaM binding sequence. The amino acids shown in red indicate the position of hydrophobic residues that form the 1-8-14 motif. Anchor amino acids are indicated by black boxes

\section{Far-western blot analysis}

Binding of the truncated and mutant proteins to CaM were assayed using Far-Western blot analysis. To identify the CaM-binding domain, we transferred CNA and its truncated proteins to nitrocellulose and verified their binding characteristics to $\mathrm{CaM}$. The deletion mutant $\triangle \mathrm{CNAb}$ (with deletion from S454 to A639) was detected to bind to $\mathrm{CaM}$, while the truncated protein $\triangle \mathrm{CNAa}$ (with deletion from R436 to A639) showed hardly any binding with $\mathrm{CaM}$ (Fig. 4a and b). This result was

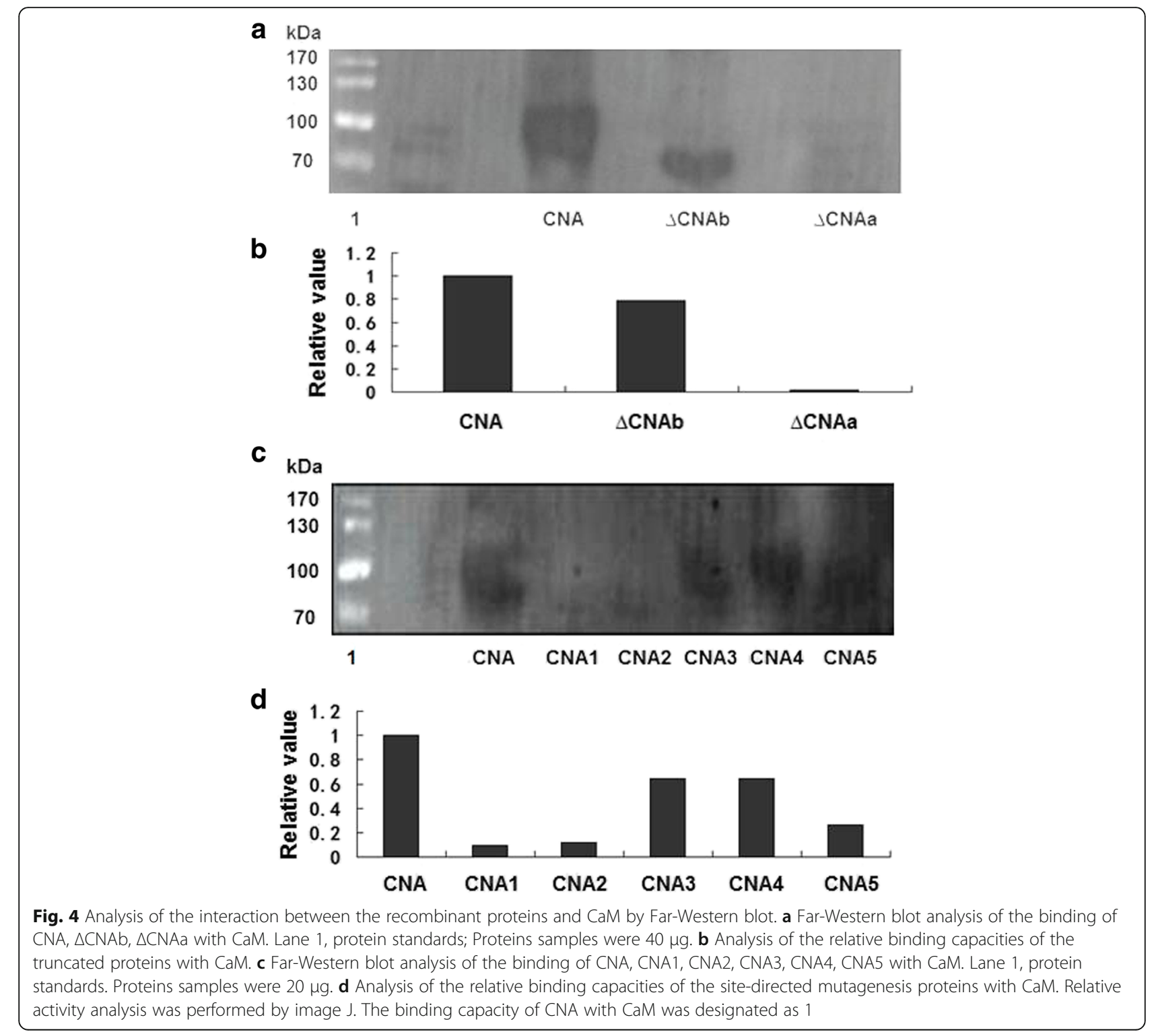


expected because $\triangle \mathrm{CNAa}$ lacks the putative CaMbinding region was detected hardly binding with CaM. The results indicated that the region between R436 and S454 was responsible for the interaction with CaM.

To determine which amino acid(s) in the CaMbinding domain was essential for the interaction with $\mathrm{CaM}$, we mutated five conserved hydrophobic amino acids and found that all the five mutated proteins could bind with CaM (Fig. 4c). The binding capacity of CNA with $\mathrm{CaM}$ was stronger than that of the mutant proteins, while the binding capacity of CNA1 and CNA2 were the lowest of the five mutants (Fig. 4d). These results indicated that the conserved hydrophobic residues, I439, I443, V446, V452, and F453 all play a role in binding to CaM, while I439 and I443 are the most important amino acids involved in binding to CaM.

\section{The effect of the CaM-binding domain on the phosphatase} activity of CNA

To determine the role of the CaM-binding domain in the activation of the phosphatase activity of CNA, the activities of CNA and its mutants were measured by a PNPP assay. The phosphatase activity of CNA was designated as 1 . As shown in (Fig. 5), the activity of the truncated protein $\triangle \mathrm{CNAa}$ was greatly decreased and proved to be the lowest among all of these mutant proteins. The phosphatase activity of CNA1 and CNA2 was also decreased and lower than the other three site-directed mutant proteins and the wild-type protein. These results suggest that the region from R436 to A639, Ile439 and Ile443 are not only important for binding to CaM but also for activation of the phosphatase activity.

\section{Al resistance of transgenic yeast}

To determine if $C N A$ can confer $\mathrm{Al}$ tolerance in the transgenic yeast, a transgenic strain designated as ScpYES3-CNA was generated. The expression of the CNA protein in the transgenic yeast was verified by Western blot (data not shown). A control strain named ScpYES3/CT containing an empty vector and the transgenic strain were treated with different concentrations of Al. The results showed that the transgenic yeast grew better than the control strain on plates with or without $\mathrm{Al}$. The transgenic yeast formed much bigger colonies than the control yeast when increasing the Al concentration. In the presence of different $\mathrm{Al}$ concentrations, the colonies formed by the transgenic strain were still much bigger than the colonies formed by the control strains (Fig. 6). The growth of transgenic yeast and control yeast was assayed in liquid broth with $2 \mathrm{mM} \mathrm{Al}^{3+}$. Within the first $20 \mathrm{~h}$, there was no significant difference between the growth of control and transgenic strains. During the stationary phase, the transgenic yeast grew better than the control yeast (Fig. 7). These results suggest that CNA conferred Al tolerance in yeast.

\section{Detection of residual $\mathrm{Al}$ in culture}

To explore the reason for $\mathrm{Al}$ tolerance in the transgenic yeast, the residual levels of active $\mathrm{Al}$ in the culture after incubation of the yeast strains was determined. The transgenic yeast Sc-pYES3-CNA and the control yeast Sc-pYES3/CT were cultured in broth medium containing $0.2 \mathrm{mM}$ and $2 \mathrm{mM} \mathrm{Al}^{3+}$. The residual $\mathrm{Al}$ levels in the supernatant were measured after eliminating the yeast cells. Uninoculated media was shaken and used as a negative control, and the residual $\mathrm{Al}$ content in this negative control was designated as $100 \%$. The residual $\mathrm{Al}$ content in the medium containing $0.2 \mathrm{mM} \mathrm{Al}^{3+}$ and the transgenic yeast in culture was significantly reduced to $33.54 \%$ of the initial content (Fig. 8a). The residual $\mathrm{Al}$ content in the medium containing $2 \mathrm{mM} \mathrm{Al}^{3+}$ with the transgenic yeast in culture was also significantly reduced to $74.19 \%$ of the initial content (Fig. 8b). The residual $\mathrm{Al}$ in culture of control yeast had a slight reduction

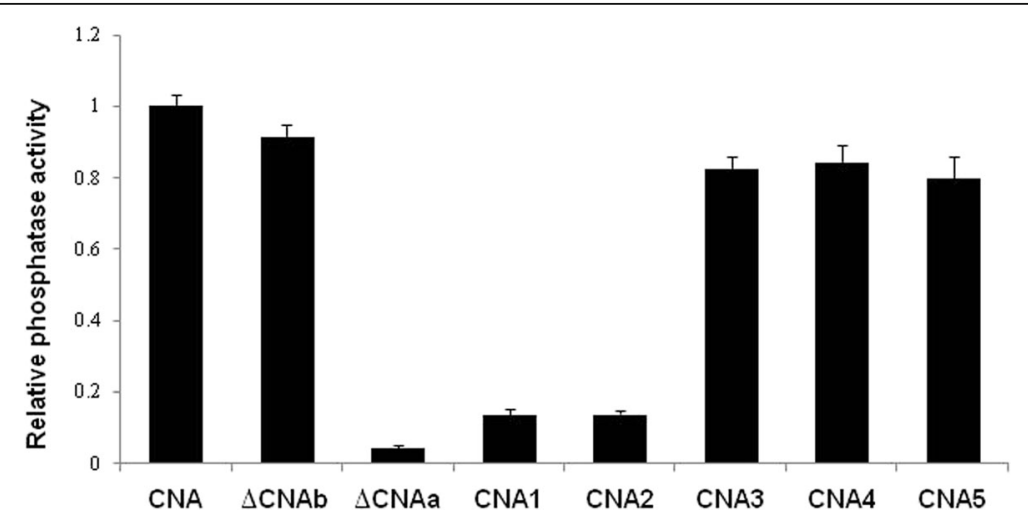

Fig. 5 Comparison of the phosphatase activity of the mutant proteins with CNA. The molar ratio of CaM to CNA or its mutant proteins was 2:1. The absorbance was read at $410 \mathrm{~nm}$. The activity of CNA was designated as 1 . The experiments were repeated three times, and a representative set of data is shown 


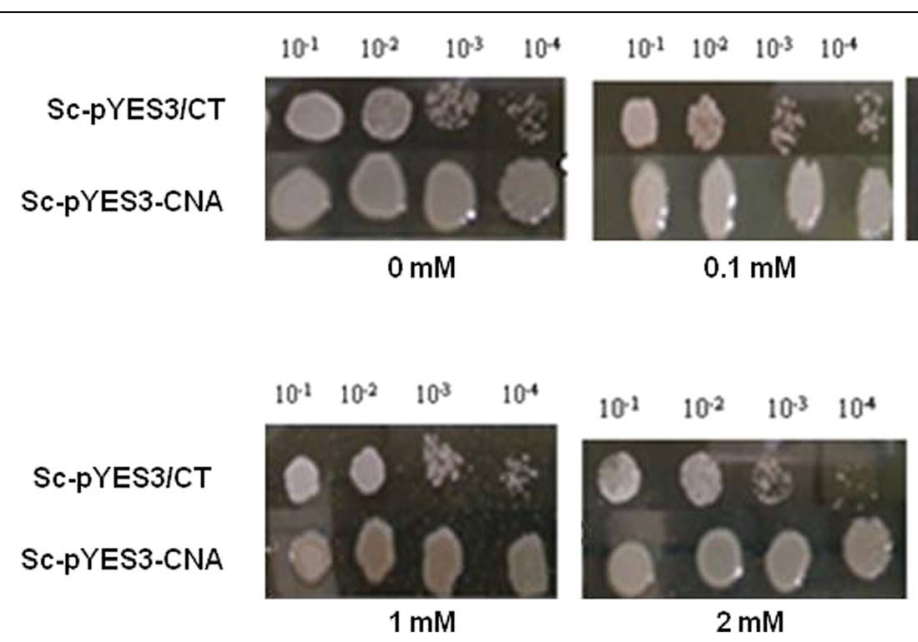

Fig. 6 Growth of transgenic yeast on solid media under Al stress. Yeast cells were pre-incubated in SC-liquid medium containing $2 \%$ (w/v) glucose to an $\mathrm{OD}_{600}$ of 2.0. Ten-fold serial dilutions were prepared (1:10, 1:100, 1:1000 and 1:10,000), and $5 \mu \mathrm{L}$ of each dilution was spotted onto SC-trp medium supplemented with $2 \%(\mathrm{w} / \mathrm{v})$ galactose and $0 \mathrm{mM}, 0.1 \mathrm{mM}, 0.2 \mathrm{mM}, 1 \mathrm{mM}$, or $2 \mathrm{mM} \mathrm{Al}{ }^{3+}$. The results were recorded after the cultures were incubated at $30^{\circ} \mathrm{C}$ for 3 days

probably due to weak absorption of the cells. Compared with the control strain, 40.36 and $14.78 \%$ of the initial $\mathrm{Al}$ content was removed by the transgenic yeasts when cultured in medium containing $0.2 \mathrm{mM}$ and $2 \mathrm{mM} \mathrm{Al}^{3+}$, respectively. We speculated that the transfer of $C N A$ might promote the yeast to absorb the active $\mathrm{Al}$ from the culture. The adsorption of $\mathrm{Al}$ onto the cell surface or on the inside of the cells will need to be investigated further.

\section{Discussion}

Several CaM-binding proteins, such as neuromodulin, myosin and calcineurin, have been identified in mammalian tissues. In this study, we characterized calcineurin from C. humicola. Yap et al. [11] had built a CaM target database (http://calcium.uhnres.utoronto.ca/ctdb) [10] based on CRS motifs structural and sequence information.
In the present study, we identified a putative CaM-binding domain in $\mathrm{CaN}$ and five key amino acids responsible for the interaction between $\mathrm{CaN}$ and $\mathrm{CaM}$ based on the database.

Our predicted result showed that conserved hydrophobic residues in the CaM-binding domain formed 1-8-14 motif. Because alanine has a relatively stable conformation and has little impact on the properties of the protein [31], we substituted alanine for each of these five amino acids in the CaM-binding domain. We found that these five amino acids were associated with CaM binding, and I439 and I443 were identified as the most important amino acids involved in binding to CaM. The positions of these five hydrophobic residues in the CaMbinding domain are similar to their counterparts in short peptides. I396, I400, I403, V409, and F410 play an important role in binding with CaM [32]. These results

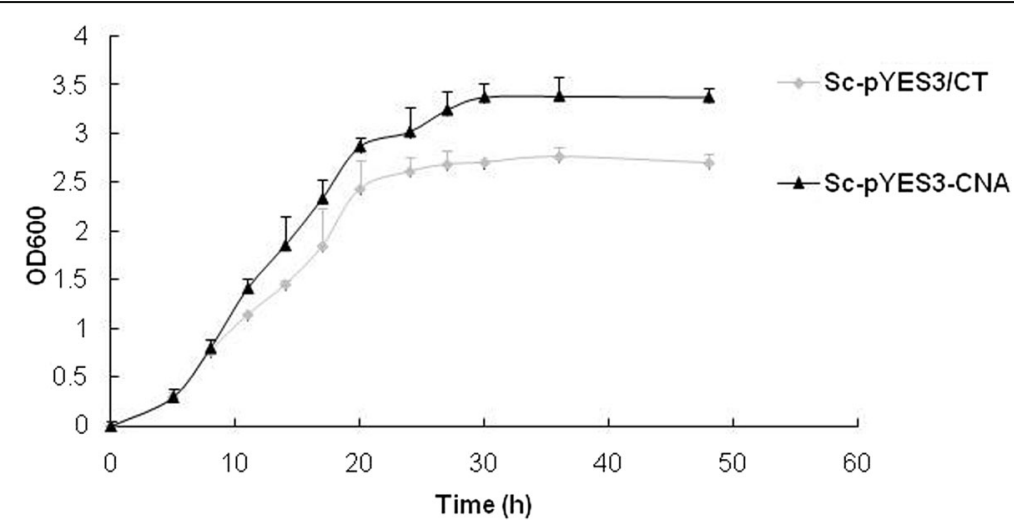

Fig. 7 Al-tolerance analysis of transgenic yeast in liquid culture. The initial $\mathrm{OD}_{600}$ was adjusted to 0.05 . The culture was then incubated at $30{ }^{\circ} \mathrm{C}$ while shaking at 200 rpm. The $\mathrm{OD}_{600}$ was measured every $2 \mathrm{~h}$. Each sample was in triplicate, and three independent experiments were conducted. Vertical bars represent standard deviations of the means $(n=3)$ 

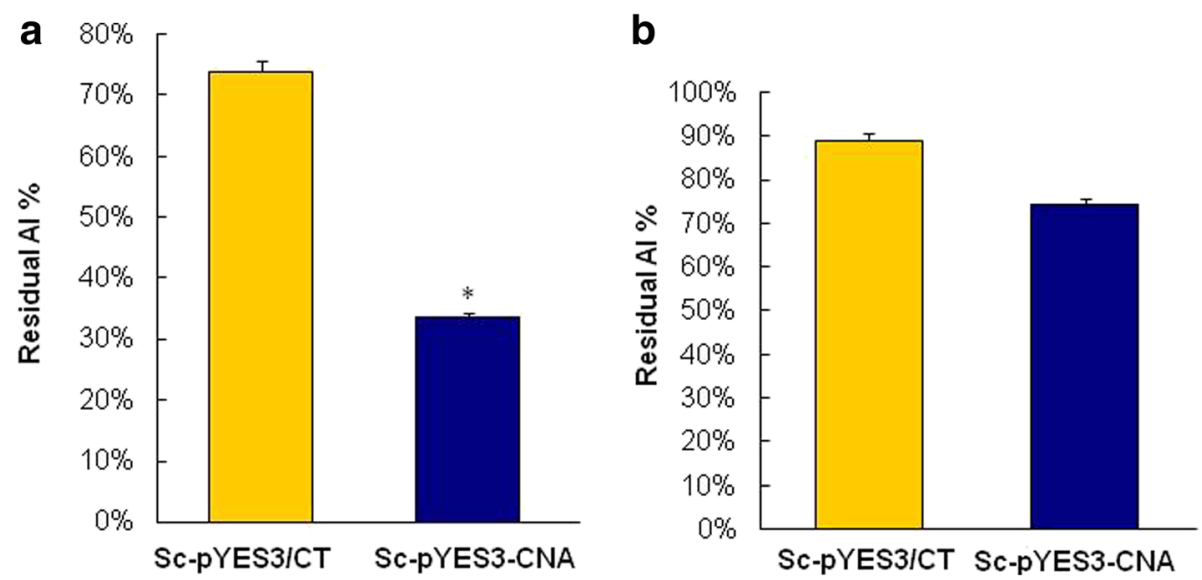

Fig. 8 Assay of residual $\mathrm{Al}$ in the culture after incubation with transgenic yeast in the presence of $0.2 \mathrm{mM} \mathrm{Al}^{3+}$ (a) or $2 \mathrm{mM} \mathrm{Al}^{3+}$ (b). Uninoculated media was shaken and used as a negative control. The residual Al in the negative control was designated as 100\%. All values are the means of three replicates. Asterisks represent significant differences when compared with the controls $(P<0.05)$

provide insight into the interactions between $\mathrm{CaM}$ and CaM-binding proteins.

Several studies have demonstrated that signal pathways are involved in $\mathrm{Al}$ tolerance in $S$. cerevisiae and $R$. glutinis, including the SLT2 mitogen-activated protein kinase signal transduction pathway, the calmodulindependent protein phosphatase (calcineurin) signaling pathways and the calmodulin-dependent protein kinase $[30,33,34]$. Cyclosporin A is an inhibitor of calcineurin. The addition of cyclosporin A completely inhibited the growth of R. glutinis under Al stress. Our work demonstrated how the gene encoding calcineurin is involved in response to the aluminum stress and resistance to aluminum toxicity.

Previous studies have demonstrated that cell walls contributed to metal ion tolerance in fungi, such as $\mathrm{Cd}$, $\mathrm{Zn}, \mathrm{Ni}, \mathrm{Cu}$ and $\mathrm{Hg}$ resistance [35-39]. Al stress also led to the increased thickness of the cell walls in Rhodotorula sp. RS1. The thickened cell walls contained $78 \%$ of the intracellular $\mathrm{Al}$ [40]. Calcineurin is required for cell wall biosynthesis. A variety of cell wall synthetic genes, such as genes encoding chitin synthase type I, 1,3- $\beta$-glucan synthesis regulator $R H O 1$ and 1,3- $\beta$-glucan synthase are regulated by the calcineurin/Crz1 signal pathway [41]. In C. albicans, calcineurin is also important for FKS1, the $\beta-1,3$ glucan synthase subunit [42]. Expression of $F K S 1$ encoding a component of the $\beta$-1,3-glucan synthase complex was increased in the $C$. neoformans cnb1 mutant [43]. Fortwendel et al. reported that calcineurin signaling regulated chitin synthases at the transcriptional level [44]. The cell wall was thicker in all of the calcineurin deletion mutants of A. fumigatus [45]. In this study, residual $\mathrm{Al}$ in the medium containing $\mathrm{CNA}$ transgenic yeast in culture was significantly reduced compared to the original $\mathrm{Al}$ content in the medium. Therefore, we speculate that $\mathrm{Al}$ may be absorbed by the cell walls of the transgenic yeast. Whether $\mathrm{CNA}$ increases $\mathrm{Al}$ resistance through cell wall biosynthesis is currently being studied in our laboratory.

\section{Conclusions}

In this study, FK506 inhibited the growth of C. humicola and the expression of $C N A$ was upregulated under $\mathrm{Al}$ stress indicating that $\mathrm{CNA}$ involved in $\mathrm{Al}$ response. We used deletion and mutagenesis method to prove that the region between R436 and S454 is essential for the interaction with CaM and I439, I443 are key amino acids in this region responsible for interaction with CaM. When introduced into yeast, $C N A$ could confer resistance to $\mathrm{Al}$. The possible mechanism of $\mathrm{Al}$ tolerance is absorption of active Al.

\section{Methods}

Strains and culture conditions

C. humicola BSLL1-1 is an Al-resistant yeast that was isolated from acidic soil [29]. C. humicola cells were cultured at $30{ }^{\circ} \mathrm{C}$ in $\mathrm{GM}$ medium with $\mathrm{pH} 3.0$ (glucose, $1.0 \%$; peptone, $0.05 \%$; yeast extract, $0.02 \%$ and $\mathrm{MgSO}_{4}$. $\left.7 \mathrm{H}_{2} \mathrm{O}, 0.02 \%\right)$ and supplemented with different concentrations of $\mathrm{Al}^{3+}$ when necessary [46]. Escherichia coli Trans1-T1 (TransGen Biotech, Beijing, China) was used for the genetic cloning. The pET-32a $(+)$ and pGEX4 T-1 plasmids were used for construction of expression vectors. E. coli BL21 (DE3) (Invitrogen, USA) was used for recombinant protein expression. The yeast expression vector pYES3/CT and $S$. cerevisiae strain INVSc1 (MATa his3D1 leu2 trp1-289 ura3-52) were used to generate transgenic yeast (Invitrogen, USA). 


\section{Growth assays with addition of FK506}

Cells were cultured until they reached an $\mathrm{OD}_{600}$ of approximately 1.0. The initial $\mathrm{OD}_{600}$ was adjusted to 0.05 , and then the inhibitor of CaN tacrolimus (FK506) was added to the culture at a final concentration of $1 \mu \mathrm{g} / \mathrm{mL}$. The cells were then incubated at $30{ }^{\circ} \mathrm{C}$ while shaking at $200 \mathrm{rpm}$. The $\mathrm{OD}_{600}$ of the cultures was measured every $2 \mathrm{~h}$ using a spectrophotometer (SHIMADZU, UV-1700, Japan). Each sample was tested in triplicate, and three independent experiments were conducted.

\section{Expression analysis of CNA at transcriptional and translational level}

To detect the expression of the CNA gene at transcriptional level, qRT-PCR was conducted. RNA was extracted from cells treated with $5,20,50,100$, or $150 \mathrm{mM}$ $\mathrm{Al}^{3+}$ for $12 \mathrm{~h}$ and cells treated with $50 \mathrm{mM} \mathrm{Al}^{3+}$ for $12 \mathrm{~h}, 24 \mathrm{~h}, 36 \mathrm{~h}$, or $48 \mathrm{~h}$ using RNAiso Plus (TaKaRa, Dalian). PrimeScript ${ }^{\mathrm{TM}}$ RT reagent Kit was used for synthesizing the first strand cDNA (TaKaRa, Dalian) according to the manufacturer's instructions. The cDNA was used as a template for PCR amplification of the CNA gene with a specific primer pairs CNA-qRT-F and CNA-qRT-R (Table 1). 18S rDNA amplified with the $18 \mathrm{~S}-\mathrm{F}$ and $18 \mathrm{~S}-\mathrm{R}$ primers (Table 1 ) was used as an internal control. Each sample was tested in triplicate.

To detect the expression level of CNA protein under $\mathrm{Al}$ stress, the protein samples were prepared from cells treated with $5,20,50,100$, or $150 \mathrm{mM} \mathrm{Al}^{3+}$ for $12 \mathrm{~h}$ using a Total Protein Extraction kit (Sigma). $500 \mu \mathrm{g}$ of total protein was separated using SDS-PAGE (12\%) and then transferred to PVDF-P membranes. The membranes were probed for mouse antibodies against CNA with peroxidase-conjugated goat antibodies against mouse IgG. The antibodies were obtained using the polypeptides of CNA (RLAEVISSPTKGGQGER).

\section{GST-pull down and Western blot analysis}

Purified glutathione S-transferase tagged CaM protein (GST-CaM) was used to study the interaction between CaM and CNA. $50 \mu \mathrm{g}$ of purified GST-CaM and $500 \mu \mathrm{g}$ of total protein from cells treated by 5, 20, 50, 100, $150 \mathrm{mM} \mathrm{Al}{ }^{3+}$ for $12 \mathrm{~h}$ were added into binding buffer (50 mM Tris-Cl, pH 7.5, $100 \mathrm{mM} \mathrm{NaCl}, 0.25 \%$ Triton X100, $1 \mathrm{mM}$ EDTA, and $1 \mathrm{mM}$ DTT) and then incubated at room temperature for $2 \mathrm{~h}$. $30 \mu \mathrm{L}$ GST agarose resin was added into the above mixture to bind overnight while shaking at $4{ }^{\circ} \mathrm{C}(40 \mathrm{rpm} / \mathrm{min})$. The precipitate was collected by centrifugation at $4{ }^{\circ} \mathrm{C}, 3500 \times \mathrm{g}$ for $5 \mathrm{~min}$, and then washed three times using the binding buffer. $10 \mu \mathrm{L}$ SDS gel loading buffer (Tris- $\mathrm{HCl} 50 \mathrm{mM}$, pH 6.8; SDS 2\%; DTT $100 \mathrm{mM}$; 0.1\% bromophenol blue; and $10 \%$ glycerol) was added to the sedimented protein mixture, and the mixtures were boiled in boiling water bath for $10 \mathrm{~min}$. The proteins were separated on a 12\% SDS -PAGE gel. The separated proteins were transferred to PVDF membrane, and then incubated with anti-CNA antibodies and a specific polyclonal anti-CaM antibody. The results were imaged using a Chemidoc XRS (BIO$\mathrm{RAD})$. The antibodies against $\mathrm{CaM}$ were prepared with purified $\mathrm{CaM}$ proteins as described below.

\section{Construction of expression vectors}

Total RNA was isolated from C. humicola by using Trizol reagent (Invitrogen, USA) according to the manufacturer's instructions. Then, DNase I (Promega, USA) was used to remove residual genomic DNA contamination in the RNA. The quality of the RNA was examined by gel electrophoresis. cDNA was synthesized using M-MLV reverse transcriptase (Fermentas, Lithuania).

Gene fragments of $\mathrm{CaM}$ and $\mathrm{CNA}$ were generated by PCR amplification. The primers were listed in Table 1 . Both fragments were cloned into a pMD-18 $\mathrm{T}$ vector (TaKaRa, Japan) to generate pMD-18 T-CaM and pMD18 T-CNA. These plasmids were used for gene sequencing to verify their sequence. The CaM encoding gene was obtained from pMD-18 T-CaM digested with EcoRI and XhoI. The CNA encoding gene was obtained by digesting pMD-18 T-CNA with the EcoRI and NotI. The $\mathrm{CaM}$ fragment was then ligated into the pGEX-4 T-1 vector between the EcoRI and XhoI sites to generate pGEX-4. T-1-CaM.

To generate truncated constructions of CNA, $\triangle \mathrm{CNAa}$ and $\triangle$ CNAb containing the 1-1284 bp and 1-1362 bp fragments of CNA were amplified using the primer pairs CNAa-F and CNAa-R, and CNAb-F and CNAb-R, respectively. $\triangle \mathrm{CNAa}$ and $\triangle \mathrm{CNAb}$ were cloned into pET$32 \mathrm{a}(+)$ to produce pET-32a- $\triangle \mathrm{CNAa}$ and pET-32a$\triangle \mathrm{CNAb}$, respectively. The difference between the two deletion mutants is whether or not they include the putative CaM binding domain.

For site-directed mutagenesis, mutations were generated using a QuikChange site-directed mutagenesis kit (TransGen, Beijing, China) according to the manufacturer's instructions. We replaced five amino acids that were predicted to interact to $\mathrm{CaM}$ with alanine according to the literature [47] (I439 to A439, I443 to A443, V446 to A446, V452 to A452, and F453 to A453). The corresponding fragments were designated as CNA1, CNA2, CNA3, CNA4 and CNA5, respectively. Sitedirected mutagenesis of these residues was performed using the mutagenic primers listed in Table 1. The mutated sequences were verified by sequence analysis. The CNA, CNA1, CNA2, CNA3, CNA4, and CNA5 fragments were ligated into the pET-32a $(+)$ vector between the EcoRI and Not I sites to generate pET-32a-CNA, pET-32a-CNA1, pET-32a-CNA2, pET-32a-CNA3, pET32a- CNA4, and pET-32a-CNA5. 


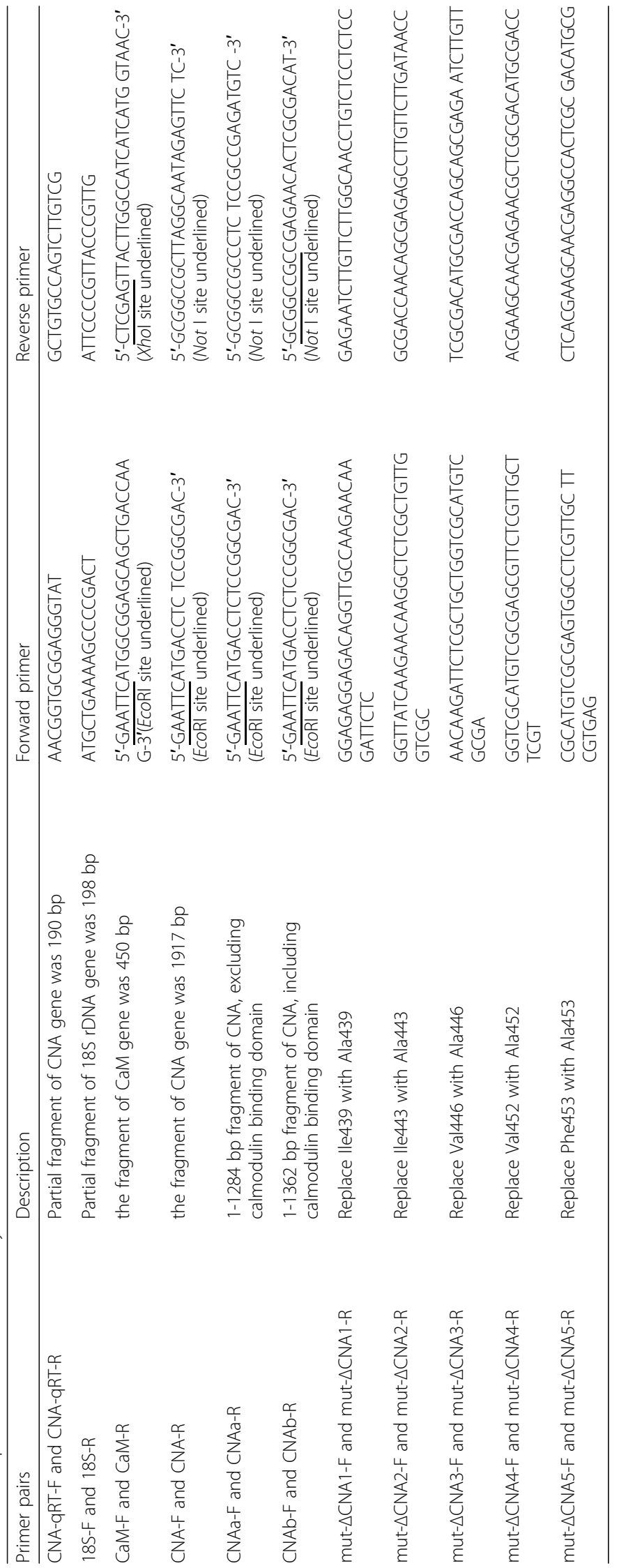




\section{Expression and purification of CaM and CNA mutant proteins}

These prokaryotic expression vectors were transformed into E. coli BL21 (DE3). For CaM recombinant protein expression, cells were grown at $37{ }^{\circ} \mathrm{C}$ in $\mathrm{LB}$ medium (10 g/L tryptone, $5 \mathrm{~g} / \mathrm{L}$ yeast extract, $10 \mathrm{~g} / \mathrm{L} \mathrm{NaCl})$ with $100 \mu \mathrm{g} / \mathrm{mL}$ ampicillin for $2 \mathrm{~h}$; then, $1 \mathrm{mM}$ IPTG was added. After growing for an additional $8 \mathrm{~h}$ at $37{ }^{\circ} \mathrm{C}$ with shaking at $80 \mathrm{rpm}$, cells were collected by centrifugation $(3000 \times \mathrm{g}$ for $5 \mathrm{~min})$. Cell pellets were resuspended in the cold PBS buffer $(137 \mathrm{mM} \mathrm{NaCl}, 2.7 \mathrm{mM} \mathrm{KCl}$, $\left.10 \mathrm{mM} \mathrm{Na} \mathrm{HPO}_{4}, 2 \mathrm{mM} \mathrm{KH_{2 }} \mathrm{PO}_{4}\right)$. The cell suspension was sonicated on ice for $7 \mathrm{~min}$ and then centrifuged at $10,000 \times \mathrm{g}$ for $15 \mathrm{~min}$ at $4{ }^{\circ} \mathrm{C}$. The supernatant and the precipitate were subjected to SDS-PAGE. Proteins were visualized by staining with Coomassie blue. CaM recombinant protein was purified from the supernatant using glutathione-agarose beads according to the manufacturer's instructions (Cwbiotech, Beijing, China). Rabbit was immunized with the purified $\mathrm{CaM}$ recombinant protein, and the anti-CaM antibodies were prepared from the immunized rabbit serum and used for Western analysis.

For CNA and CNA variant proteins expression, cells were grown at $37{ }^{\circ} \mathrm{C}$ in $\mathrm{LB}$ medium with $100 \mu \mathrm{g} / \mathrm{mL}$ ampicillin for $2 \mathrm{~h}$; then, $1 \mathrm{mM}$ IPTG was added. After growing for an additional $10 \mathrm{~h}$ at $20{ }^{\circ} \mathrm{C}$ with shaking at $80 \mathrm{rpm}$, the cells were collected by centrifugation $(3000 \times \mathrm{g}$ for $5 \mathrm{~min})$. The cell pellets were resuspended in the cold PBS buffer. The cell suspension was sonicated on ice for $7 \mathrm{~min}$ and then centrifuged at 10,000 $\times \mathrm{g}$ for $15 \mathrm{~min}$ at $4{ }^{\circ} \mathrm{C}$. Analysis of protein expression was performed in SDS-PAGE gel. His-tagged recombinant proteins were purified by affinity chromatography.

\section{Far-western analysis}

For Far-western analysis, CNA and its variant proteins were subjected to SDS-PAGE and then transferred to nitrocellulose membranes. Membranes were denatured by incubating them in $6 \mathrm{M}, 3 \mathrm{M}, 1 \mathrm{M}$ guanidine hydrochloride AC buffer (10\% Glycerol, $0.1 \mathrm{M} \mathrm{NaCl}, 20 \mathrm{mM}$ Tris- $\mathrm{HCl}, \mathrm{pH}$ 7.5, $1 \mathrm{mM}$ EDTA, 0.1\% Tween-20, 2\% Milk powder, $1 \mathrm{mM}$ DTT) for $2 \mathrm{~h}$ at room temperature with shaking at $50 \mathrm{rpm}$ and then renatured by incubating them in AC buffer without guanidine hydrochloride for $8 \mathrm{~h}$ at $4{ }^{\circ} \mathrm{C}$ while shaking at $50 \mathrm{rpm}$. After these steps, the membranes were blocked for $2 \mathrm{~h}$ at room temperature in TBST buffer $(50 \mathrm{mM}$ Tris- $\mathrm{HCl}, \mathrm{pH} 8.0$, $0.15 \mathrm{M} \mathrm{NaCl}, 0.02 \%$ Tween-20) containing 5\% milk, rinsed with distilled water, and then incubated with $1 \mu \mathrm{g} / \mathrm{mL}$ CaM in binding buffer $(50 \mathrm{mM}$ Tris- $\mathrm{HCl}$, pH 7.5, 1 mM EDTA, $100 \mathrm{mM} \mathrm{NaCl}, 1 \mathrm{mM}$ DTT, $0.25 \%$ Triton $\mathrm{X}-100)$ containing $5 \mathrm{mM} \mathrm{Ca}^{2+}$ for $6 \mathrm{~h}$ at $4{ }^{\circ} \mathrm{C}$ with shaking at $50 \mathrm{rpm}$. Anti-CaM antibodies were added to binding buffer for another $6 \mathrm{~h}$ with the same conditions to the binding step. Membranes were washed three times with TBST buffer, and then incubated for $2 \mathrm{~h}$ in TBST with secondary antibody IgGHRP (Cwbiotech, Beijing, China). CaM was bound by a CaM antibody, and then the CaM antibody was detected with horseradish peroxidase-conjugated secondary antibody and visualized using ECL reagent (Cwbiotech, Beijing, China).

\section{Assay of phosphatase activity}

The phosphatase activity of CNA was assayed using $p$-nitrophenyl (pNPP) substrate solution. The reaction solution contained $50 \mathrm{mM}$ Tris- $\mathrm{HCl}$ (pH 7.4), $0.5 \mathrm{mM}$ DTT, $0.5 \mathrm{mM} \mathrm{MnCl}_{2}, 1 \mathrm{mM} \mathrm{CaCl} 2,0.2 \mathrm{mg} / \mathrm{mL}$ bovine serum albumin, and $20 \mathrm{mM}$-nitrophenyl phosphate. The reactions were performed in a volume of $0.2 \mathrm{~mL}$ at $30{ }^{\circ} \mathrm{C}$ for $20 \mathrm{~min}$ and terminated by the addition of $1.8 \mathrm{~mL}$ of a $0.5 \mathrm{mM} \mathrm{Na} \mathrm{CO}_{3}$ and $20 \mathrm{mM}$ EDTA solution. The molar ratio of $\mathrm{CaM}$ to $\mathrm{CNA}$ or its mutants was 2:1. The absorbance was read at $410 \mathrm{~nm}$.

\section{Construction of the yeast expression vector of CNA and transgenic yeast}

To analyze the role of CNA gene in Al tolerance, the pYES3/CT yeast expression vector and the $S$. cerevisiae strain INVSc1 (MATa his3D1 leu2 trp1-289 ura3-52) were used to generate transgenic yeast. The coding region of CNA was digested from pMD-CNA with EcoRI/XhoI, and the fragments were purified and cloned into the EcoRI/ XhoI site of pYES3/CT, which carries the TRP1 selection marker. CNA expression was controlled by the inducible GAL1 promoter. Sequence analysis was used to confirm the insertion of $C N A$ into the pYES3/CT. The resulting pYES3-CNA and pYES3/CT empty vector were transformed into the INVSc1 S. cerevisiae strain using the lithium acetate method. The presence of the pYES3-CNA plasmid in transgenic yeast was confirmed by PCR analysis and by Western blot using CNA antibodies.

\section{Al tolerance analysis of CNA in S. cerevisiae}

The INVSc1 strain was inoculated from colonies on yeast extract peptone dextrose (YPD) medium plates (yeast extract $10 \mathrm{~g}$, peptone $20 \mathrm{~g}$, glucose $20 \mathrm{~g}$, agar $20 \mathrm{~g}$, and $1,000 \mathrm{~mL}$ water) and grown for 3 days at $30^{\circ} \mathrm{C}$. The transformants were grown on selective culture medium that lacked tryptophan (SC-trp: $0.67 \%$ yeast nitrogen base without amino acids but containing ammonium sulfate; $2 \%$ glucose; $0.01 \%$ (adenine, arginine, cysteine, leucine, lysine, threonine and uracil); 0.005\% (aspartic acid, histidine, isoleucine, methionine, phenylalanine, proline, serine, tyrosine, and valine); and $2 \%$ agar) for 2 days at $30{ }^{\circ} \mathrm{C}$, and the resulting $\operatorname{trp}^{+}$colonies were selected for further research. 
For the $\mathrm{Al}$ tolerance assays, yeast cells harboring pYES3-CNA and the empty vector pYES3/CT (control) were pre-incubated in SC-liquid medium containing $2 \%$ $(\mathrm{w} / \mathrm{v})$ glucose at $30{ }^{\circ} \mathrm{C}$ until they reached an $\mathrm{OD}_{600}$ of approximately 2.0. Then, 10-fold serial dilutions were prepared (1:10, 1:100, 1:1000 and 1:10,000), and $5 \mu \mathrm{L}$ of each dilution was spotted onto SC-trp medium supplemented with $2 \%(\mathrm{w} / \mathrm{v})$ galactose and $0 \mathrm{mM}, 0.1 \mathrm{mM}$, $0.2 \mathrm{mM}, 1 \mathrm{mM}$, or $2 \mathrm{mM} \mathrm{Al}^{3+}$. The cultures were incubated at $30{ }^{\circ} \mathrm{C}$ for 3 days. Each sample was spotted in triplicate, and three independent experiments were conducted. The INVSc1 strain containing pYES3/CT was used as a control. To assay the growth in liquid broth supplemented with $2 \mathrm{mM} \mathrm{Al}^{3+}$, the initial $\mathrm{OD}_{600}$ was adjusted to 0.05 and then the yeasts were incubated at $30{ }^{\circ} \mathrm{C}$ while shaking at $200 \mathrm{rpm}$. The $\mathrm{OD}_{600}$ of the cultures was measured every $2 \mathrm{~h}$ using a spectrophotometer (SHIMADZU, UV-1700, Japan).

\section{Residual Al content assays}

Yeast cells harboring pYES3/CT-CNA and pYES3/CT were incubated overnight in SC-liquid medium containing $2 \%(\mathrm{w} /$ v) glucose and were then transferred to YPD medium containing $0.2 \mathrm{mM}$ or $2 \mathrm{mM} \mathrm{Al}^{3+}$ with an initial $\mathrm{OD}_{600}$ of 0.1 . After $24 \mathrm{~h}$ of incubation, the culture was centrifuged at $12,000 \mathrm{rpm}$ for $10 \mathrm{~min}$, and the supernatant was filtered using a sterilized filter with $0.2 \mu \mathrm{m}$ pores. The levels of inorganic monomeric $\mathrm{Al}$ and total $\mathrm{Al}$ in the filtered supernatant were determined according to the method described by Nian et al. [29]. The analyses were performed in duplicate.

\section{Abbreviations}

AID: autoinhibitory domain; Al: aluminum; CaN: calcineurin; CaM: calmodulin; CNA: catalytic subunit A; CNB: regulatory subunit B; CRS: CaM recruitment signaling; ER: endoplasmic reticulum; SC-trp: selective culture medium lacked tryptophan; YPD: yeast extract peptone dextrose

\section{Acknowledgements}

We thank Dr. Papadopoulos Vassilios (The Research Institute of the McGill University Health Center, Canada) for providing the yeast expression vector pYES3/CT and the S. cerevisiae INVSC1 (MATa his3D1 leu2 trp1-289 ura3-52) strain.

\section{Funding}

This work was supported by the National Natural Science Foundation of China (31160020 and 31560246).

\section{Availability of data and materials}

The datasets used and analysed during the current study are available from the corresponding author on reasonable request. The CaM target database used in this study is available on website (http://calcium.uhnres.utoronto.ca/ ctdb). The CNA sequence has been submitted to GenBank database. The accession number is KJ738305.

\section{Authors' contributions}

HJN designed the study and wrote the paper. JJZ performed the experiments and analyzed the data shown in Figs. 1, 2c,d and 7. LZ performed the experiments and analyzed the data shown in Figs. 3, 4 and 5. $S L$ performed the experiments and analyzed the data shown in Figs. 2a,b, 6 and 8 . LMC provided technical assistance. All of the authors reviewed the results and approved the final version of the manuscript.

\section{Competing interests}

The authors declare that they have no competing interests.

\section{Consent to publication}

Not applicable.

Ethics approval and consent to participate

Not applicable.

\section{Publisher's Note}

Springer Nature remains neutral with regard to jurisdictional claims in published maps and institutional affiliations.

Received: 7 September 2016 Accepted: 8 March 2017

Published online: 29 March 2017

\section{References}

1. Evenäs J, Malmendal A, Forsén S. Calcium. Curr Opin Chem Biol. 1998;2:293-302.

2. Crivici A, Ikura M. Molecular and structural basis of target recognition by calmodulin. Annu Rev Biophys Biomol Struct. 1995;24:85-116.

3. Schulman H, Greengard P. Stimulation of brain membrane protein phosphorylation by calcium and an endogenous heat-stable protein. Nature. 1978;271:478-9.

4. DeLorenzo RJ, Freedman SD, Yohe WB, Maurer SC. Stimulation of $\mathrm{Ca}^{2}$ ${ }^{+}$-dependent neurotransmitter release and presynaptic nerve terminal protein phosphorylation by calmodulin and a calmodulin-like protein isolated from synaptic vesicles. Proc Natl Acad Sci. 1979;76:1838-42.

5. Goldenring JR, Gonzalez B, McGuire Jr JS, DeLorenzo RJ. Purification and characterization of a calmodulin-dependent kinase from rat brain cytosol able to phosphorylate tubulin and microtubule-associated proteins. J Biol Chem. 1983;258:12632-40.

6. Hu L, Zhang B, Xiang B, Wei Q. Calcineurin B protects calcineurin A against denaturation by urea. Biochim Biophys Acta. 2004;1700:141-4.

7. Klee $C B$, Ren $H$, Wang $X$. Regulation of the calmodulin-stimulated protein phosphatase, calcineurin. J Biol Chem. 1998;273:13367-70.

8. Yang SA, Klee CB. Low affinity $\mathrm{Ca}^{2+}$-binding sites of calcineurin B mediate conformational changes in calcineurin A. Biochemistry. 2000;39:16147-54.

9. Ye Q, Feng Y, Yin Y, Faucher F, Currie MA, Rahman MN, Jin J, Li S, Wei Q, Jia Z. Structural basis for activation of calcineurin by calmodulin. J Mol Biol. 2002:415:307-17.

10. The CaM target database. http://calcium.uhnres.utoronto.ca/ctdb. This database published on March 2003.

11. Yap KL, Kim J, Truong K, Sherman M, Yuan T, Ikura M. Calmodulin target database. J Struct Funct Genomics. 2000;1:8-14.

12. Hirata $\mathrm{D}$, Harada $\mathrm{S}$, Namba H, Miyakawa T. Adaptation to high-salt stress in Saccharomyces cerevisiae is regulated by $\mathrm{Ca}^{2+} /$ calmodulin-dependent phosphoprotein phosphatase (calcineurin) and CAMP-dependent protein kinase. Mol Gen Genet. 1995;249:257-64.

13. lida H, Ohya Y, Anraku Y. Calmodulin-dependent protein kinase II and calmodulin are required for induced thermotolerance in Saccharomyces cerevisiae. Curr Genet. 1995;27:190-3.

14. Moser MJ, Geiser JR, Davis TN. $\mathrm{Ca}^{2+}$-calmodulin promotes survival of pheromone-induced growth arrest by activation of calcineurin and $\mathrm{Ca}^{2}$ ${ }^{+}$-calmodulin-dependent protein kinase. Mol Cell Biol. 1996;16:4824-31.

15. Breuder T, Hemenway CS, Movva NR, Cardenas ME, Heitman J. Calcineurin is essential in cyclosporin A- and FK506-sensitive yeast strains. Proc Natl Acad Sci U S A. 1994;91:5372-6.

16. Hemenway CS, Dolinski K, Cardenas ME, Hiller MA, Jones EW, Heitman J. vph6 mutants of Saccharomyces cerevisiae require calcineurin for growth and are defective in vacuolar Ht-ATPase assembly. Genetics. 1995;141:833-44.

17. Cunningham KW, Fink GR. Calcineurin inhibits VCX1-dependent $\mathrm{H}^{+} / \mathrm{Ca}^{2+}$ exchange and induces $\mathrm{Ca}^{2+}$ ATPases in Saccharomyces cerevisiae. Mol Cell Biol. 1996;16:2226-37.

18. Matheos DP, Kingsbury TJ, Ahsan US, Cunningham KW. Tcn1p/Crzlp, a calcineurin-dependent transcription factor that differentially regulates gene expression in Saccharomyces cerevisiae. Genes Dev. 1997;11:3445-58.

19. Mendoza I, Quintero FJ, Bressan RA, Hasegawa PM, Pardo JM. Activated calcineurin confers high tolerance to ion stress and alters the budding pattern and cell morphology of yeast cells. J Biol Chem. 1996;271:23061-7. 
20. Zhao C, Jung US, Garrett-Engele P, Roe T, Cyert MS, Levin DE. Temperatureinduced expression of yeast FKS2 is under the dual control of protein kinase C and calcineurin. Mol Cell Biol. 1998;18:1013-22.

21. Marquina M, González A, Barreto L, Gelis S, Muñoz I, Ruiz A, Alvarez MC, Ramos J, Ariño J. Modulation of yeast alkaline cation tolerance by Ypi1 requires calcineurin. Genetics. 2012;190:1355-64.

22. Bonilla M, Nastase KK, Cunningham KW. Essential role of calcineurin in response to endoplasmic reticulum stress. EMBO J. 2002;21:2343-53.

23. Zelter A, Bencina M, Bowman BJ, Yarden O, Read ND. A comparative genomic analysis of the calcium signaling machinery in eurospora crassa, Magnaporthe grisea, and Saccharomyces cerevisiae. Fungal Genet Biol. 2004;41:827-41.

24. Stie J, Fox D. Calcineurin regulation in fungi and beyond. Eukaryot Cell. 2008;7:177-86

25. Araki $Y$, Wu H, Kitagaki $\mathrm{H}$, Akao T, Takagi $\mathrm{H}$. Ethanol stress stimulates the $\mathrm{Ca}^{2}$ ${ }^{+}$mediated calcineurin/Crz1 pathway in Saccharomy cescerevisiae. J Biosci Bioeng. 2009;107:1-6.

26. Da Silva Ferreira ME, Heinekamp T, Härtl A, Brakhage AA, Semighini CP, Harris SD, Savoldi M, de Gouvêa PF, de SouzaGoldman MH, Goldman GH. Functional characterization of the Aspergillus fumigatus calcineurin. Fungal Genet Biol. 2007:44:219-30.

27. Bader T, Bodendorfer B, Schröppel K, Morschhäuser J. Calcineurin is essential for virulence in Candidaal bicans. Infect Immun. 2003;71:5344-54.

28. Blankenship JR, Wormley FL, Boyce MK, Schell WA, Filler SG, Perfect JR, Heitman J. Calcineurin is essential for Candida albicans survival in serumand virulence. Eukaryot Cell. 2003;2:422-30.

29. Nian HJ, Wang GQ, Zhao LW, YU YX, Li KZ, Chen LM. Isolation of Al-tolerant yeasts and identification of their Al-tolerance characteristics. J Biol Res-Thessalon. 2012;18:227-34.

30. Tani A, Kawahara T, Yamamoto Y, Kimbara K, Kawai F. Genes involved in novel adaptive aluminum resistance in Rhodotorula glutinis. J Biosci Bioeng. 2010;109:453-8.

31. Morrison KL, Weiss GA. Combinatorial alanine-scanning. Curr Opin Chem Biol. 2001;5:302-7.

32. Ye Q, Li X, Wong A, Wei Q, Jia Z. Structure of calmodulin bound to a calcineurin peptide: a new way of making an old binding mode. Biochemistry. 2006:45:738-45.

33. Tani A, Inoue C, Tanaka Y, Yamamoto Y, Kondo H, Hiradate S, Kimbara K, Kawai $F$. The crucial role of mitochondrial regulation in adaptive aluminium resistance in Rhodotorula glutinis. Microbiology. 2008;154:3437-46.

34. Schott EJ, Gardner RC. Aluminum-sensitive mutants of Saccharomyces cerevisiae. Mol Gen Genet. 1997;254:63-72

35. Li ZJ, Yuan HL. Responses of Rhodotorula sp. Y11 to cadmium. Biometals. 2008;21:613-21.

36. Zapotoczny S, Jurkiewicz A, Tylko G, Anielska T, Turnau K. Accumulation of copper by Acremonium pinkertoniae, a fungus isolated from industrial wastes. Microbiol Res. 2007;162:219-28.

37. Strouhal M, Kizek R, Vacek J, Trnková L, Nemec M. Electrochemical study of heavy metals and metallothionein in yeast Yarrowia lipolytica. Bioelectrochemistry. 2003;60:29-36.

38. Ito $H$, Inouhe $M$, Tohoyama $H$, Joho M. Characteristics of copper tolerance in Yarrowia lipolytica. Biometals. 2007;20:773-80.

39. Ghosh SK, Chaudhuri J, Gachhui R, Mandal A, Ghosh S. Effect of mercury and organomercurials on cellular glucose utilization: a study using resting mercury-resistant yeast cells. J Appl Microbiol. 2007;102:375-83.

40. Wang C, Zhao XQ, Aizawa T, Sunairi M, Shen RF. High aluminum tolerance of Rhodotorula sp. RS1 is associated with thickening of the cell wall rather than chelation of aluminum ions. Pedosphere. 2013;23:29-38.

41. Adler A, Park YD, Larsen P, Nagarajan V, Wollenberg K, Qiu J, Myers TG, Williamson PR. A novel specificity protein 1 (SP1)-like gene regulating protein kinase C-1 (Pkc1)-dependent cell wall integrity and virulence factors in Cryptococcus neoformans. J Biol Chem. 2011;286:20977-90.

42. Sanglard D, Ischer F, Marchetti O, Entenza J, Bille J. Calcineurin A of Candida albicans: involvement in antifungal tolerance, cell morphogenesis and virulence. Mol Microbiol. 2003:48:959-76.

43. Kraus PR, Fox DS, Cox GM, Heitman J. The Cryptococcus neoformans MAP kinase Mpk1 regulates cell integrity in response to antifungal drugs and loss of calcineurin function. Mol Microbiol. 2003;48:1377-87.

44. Fortwendel JR, Juvvadi PR, Perfect BZ, Rogg LE, Perfect JR, Steinbach WJ, Transcriptional regulation of chitin synthases by calcineurin controls paradoxical growth of Aspergillus fumigatus in response to caspofungin. Antimicrob Agents Chemother. 2010;54:1555-63.
45. Juvvadi PR, Fortwendel JR, Rogg LE, Burns KA, Randell SH, Steinbach WJ. Localization and activity of the calcineurin catalytic and regulatory subunit complex at the septum is essential for hyphal elongation and proper septation in Aspergillus fumigatus. Mol Microbiol. 2011;82:1235-59.

46. Kawai F, Zhang D, Sugimoto M. Isolation and characterization of acid- and Al-tolerant microorganisms. FEMS Microbiol Letters. 2000;189:143-7.

47. Rhoads AR, Friedberg F. Sequence motifs for calmodulin recognition. FASEB J. 1997;11:331-40

\section{Submit your next manuscript to BioMed Central and we will help you at every step:}

- We accept pre-submission inquiries

- Our selector tool helps you to find the most relevant journal

- We provide round the clock customer support

- Convenient online submission

- Thorough peer review

- Inclusion in PubMed and all major indexing services

- Maximum visibility for your research

Submit your manuscript at www.biomedcentral.com/submit
) Biomed Central 